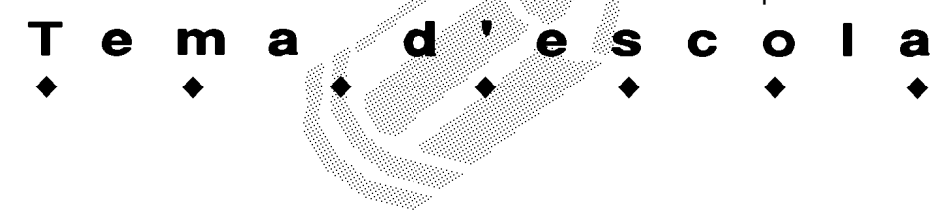

\title{
EL PLANTEJAMENT DE PREGUNTES COM A ESTRATĖGIA PER MILLORAR LA CAPACITAT ARGUMENTATIVA
}

\author{
Antoni Gavaldà (coord.) Àrea de Didàctica de les Ciències Socials. URV. \\ Carme Conde. Àrea de Psicologia Evolutiva i de l'Educació. URV. \\ Luisa Girondo. Àrea de Didàctica de les Matemàtiques. URV. \\ Albert Macaya. Àrea de Didàctica de l'Expressió Plàstica. URV. \\ Isabel Viscarro. Àrea de Didàctica de l'Expressió Corporal. URV
}

\section{Introducció}

En sintonia amb les propostes que entenen l'aprenentatge formal con un procés eminentment interactiu de negociació de significats i de construcció conjunta entre professors i alumnes, contemplem l'argumentació com una de les principals estratègies per vehicular-lo. El contrast d'opinions i raons, el qüestionament de determinades afirmacions, les refutacions $i$ els avals o proves adduïts per professors i alumnes a propòsit d'un determinat tema, entenem que són elements determinants de la construcció conjunta del coneixement. Com ja va indicar en un altre article publicat en aquesta mateixa revista (GAVALDÀ i altres, 2004) el grup de recerca de la URV "Investigació didàctica i continguts curriculars" està duent a terme una activitat de recerca sobre la capacitat argumentativa dels alumnes d'educació primària de l'ensenyament de Mestre. Aquest treball és, per tant, continuació del primer.

Com dèiem en el primer article, cal que l'alumnat sigui capaç de crear coneixement en comptes de només assimilar-lo de forma passiva, en la línia d'una construcció crítica. Aquesta acció reclama situacions docents obertes que facin possible el diàleg i el contrast d'opinions, i el planteig d'activitats d'ensenyament-aprenentatge que mobilitzin l'ús d'estratègies reflexives i interactives. Demostrar, convèncer de forma raonada, saber donar arguments a favor o en contra, assenyalar possibles conclusions, confrontar diversos punts de vista són activitats estretament relacionades amb el processament crític de la informació.

Els resultats de la primera recerca van evidenciar fortes mancances en la capacitat argumentativa de l'alumnat de magisteri. Les argumentacions eren, en general, incompletes i poc sòlides, tant pel que fa als continguts discursius com als elements de l'estructura argumentativa emprats de forma espontània. Així, d'acord amb el model d'argumentació proposat per Toulmin,
Rieke i Janik (1997) es va observar en els subjectes de la mostra una forta tendència a identificar l'argumentació amb fer una afirmació i donar algunes raons; en pocs casos es van donar avals i refutacions, i encara era menys freqüent l'ús de suports. D'altra banda, la major part de les argumentacions eren molt bàsiques i generalment expressades en llenguatge col-loquial i poc específic de l'àrea corresponent. Quedava prou clar que els alumnes necessitaven millorar la seva capacitat argumentativa i que aquesta millora incidiria de forma decisiva en la construcció crítica del coneixement.

Això ens va portar a plantejar quina podria ser l'estratègia didàctica més adequada per millorar aquesta competència. Van sorgir diverses propostes (ensenyarla de forma explícita, oferir models de bones argumentacions...) però, atès que l'argumentació és un acte comunicatiu interactiu que es dóna molt sovint en el transcurs de la classe, va semblar que la formulació de preguntes al voltant de les argumentacions dels alumnes podria ser una bona estratègia per millorar-la. Així, es tractaria de facilitar, acompanyar i millorar l'argumentació espontània mitjançant preguntes per tal d'esperonar la participació activa de l'alumnat i l'aprofundiment en el seu discurs argumentatiu (preguntes incitadores d'avals i refutacions, de modalitat, d'exemples...), de bastir l'argumentació en el context comunicatiu de la classe, i alhora, compartir amb ells el procés de construcció crítica del coneixement (construcció crítica conjunta del coneixement) i de la mateixa competència argumentativa (COLL i ONRUBIA, 2001). Conseqüentment, en aquesta segona fase hem elaborat una tipologia de preguntes i hem volgut esbrinar quines afavoriiien millor l'argumentació en les diferents àrees curriculars.

\section{Metodologia emprada}

Aquest estudi s'ha fet amb una part de la mostra inicial, integrada per 31 alumnes de l'especialitat d'educa- 


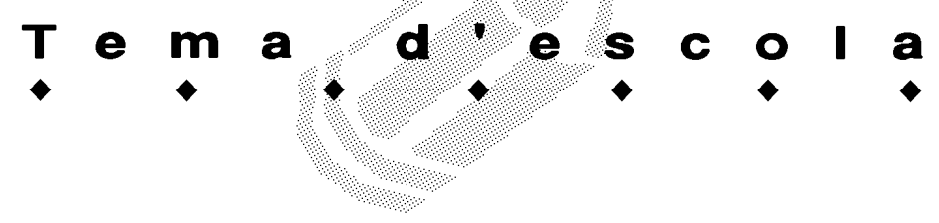

ció primària. El criteri emprat per triar-la ha estat la capacitat argumentativa demostrada en la primera fase, tant des del punt de vista dels components utilitzats en l'argumentació com del seu contingut.

Inicialment es va fer una anàlisi detallada de les respostes de tots els alumnes en cadascuna de les qüestions plantejades, la qual cosa ens va permetre establir una categorització de les respostes en quatre grups o nivells:

0 . No hi ha afirmació. Discurs argumentatiu poc coherent (costa d'entendre) i lingüísticament molt pobre.

1. Hi ha afirmació, i una o dues raons. Argumentació bàsica, expressada en llenguatge col-loquial.

2. Hi ha afirmació, raons i alguna refutació o aval. Argumentació més completa i millor expressada.

3. Hi ha afirmació, raons, refutació i aval. Argumentació clara, expressada en el llenguatge propi de l'àrea.

En aquest context, cada àrea va puntuar el resultats de la mostra. Posteriorment es va fer una anàlisi comparativa de les puntuacions per tal d'identificar alumnes amb puntuacions semblants en totes les qüestions, i entre aquests, i de forma aleatòria, es van seleccionar:

- Dos alumnes del nivell 3, considerats amb una bona argumentació: ús de més de tres components -afirmació, modalitat, raó, aval, refutació... i de més d'una raó, aval o refutació; afirmació clara i precisa; raons, refutacions i aval pertinents.

- Dos del nivell 2, seleccionats com de regular base argumentativa -ús de tres components: afirmació, raó i un aval o una refutació; afirmació menys precisa; raó, aval més febles.

- Dos del nivell 100 , considerats com de dèbil base argumentativa o fins i tot distorsionadora: ús d'un o dos components: afirmació i raó; afirmació imprecisa i raó feble.

Tipologia de les preguntes.

La tipologia de preguntes per a millorar l'argumentació prèvia es discutí en el grup i s'optà per agrupar-les en les cinc categories que a continuació es descriuen. Algunes categories eren coincidents amb les que la bibliografia marcava per al camp del treball en les ciències naturals (GÓMEZ i altres, 2004). Per a cada categoria es van descriure, a priori, quins components del discurs argumentatiu, seguint el model de Toulmin (1997), com a marc teòric de la present recerca, es tractaven de millorar. Més endavant es farà la valoració concreta del tipus de pregunta que aconseguí millors resultats en cada una de les àrees treballades. Destaquem, en primer lloc, una primera pregunta que emmarca la situació:

a) Revisió de l'argumentació prèvia.

Es tractava de recordar l'argumentació realitzada, i va servir com a punt de partida per al diàleg. L'alumne podia reafirmar-se, matisar, contradir i, en tot cas, actualitzar la qüestió a tractar i els seus punts de vista.

Van ser exemples d'aquest tipus les preguntes:

- Llegeix la teva argumentació prèvia i digues què en penses ara?

- Què canviaries del que has escrit?

Aquesta primera presa de contacte va servir a l'expert per a veure quins aspectes del discurs argumentatiu l'alumne valorava com a principals: l'afirmació pròpiament dita, les raons que la sustentaven, el fet de preveure excepcions que implicaven variar la modalitat, etc.

A continuació es passà a les altres preguntes, les que enteníem que eren les centrals, les que intentaven induir a una millora de l'argumentació.

b) Preguntes fonamentadores.

Eren preguntes que buscaven incidir en la producció de raons que justifiquessin l'afirmació. Alguns exemples d'aquest tipus eren les preguntes següents:

- Què t'ho fa pensar?

- Com en pots estar segur?

- En què et bases?

A través d'aquestes preguntes, estratègicament formulades, es pretenia que l'alumne ampliés el seu raonament, el matisés i generés raons noves que no havia previst inicialment.

Una variant d'aquest tipus de preguntes va ser el que Rickerman (2007) anomenà "devolució", en el sentit que no és pròpiament una pregunta, sinó el fet de retornar a l'entrevistat un fragment del que ha dit. Parteix de la base que quan se sospita que quan una idea enunciada per l'alumne es pot desenvolupar més, que hi ha quelcom implícit en el que ha indicat i no es vol induir la resposta, es retorna una frase o el final d'una frase enunciada per ell. En són exemples:

- Tu estàs dient que no t'agrada la democràcia que hi ha ara aquí a Catalunya?

- Dius que la línia divideix el cub en dos: com?

En una entrevista oral apareixen moltes situacions d'aquest tipus, i lògicament, amb preguntes ben formulades, es pot ajudar a millorar qualsevol dels components de l'estructura del discurs argumentatiu.

c) Preguntes focalitzadores.

Aquestes preguntes proposen un enfocament alternatiu, una perspectiva diferent de la mostrada per l'entrevistat. En van ser exemples:

- Què en diria un científic?

- Què en pensaria algú d'una altra cultura?

- Què haurien dit d'això al segle XIX?

Com que són preguntes que proposen un punt de vista nou, introdueixen un grau de generalitat més alt, i per tant, apunten cap a l'aval o la teoria en què recolza el discurs argumentatiu, ja que exigeixen un cert allunyament del fet concret. 


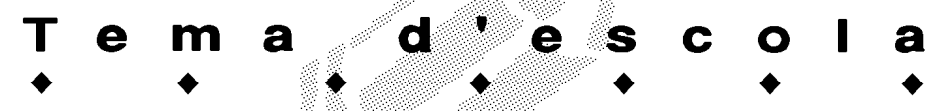

d) Preguntes d'hipòtesi.

Aquestes preguntes indueixen el subjecte a formular una hipòtesi o presenten una situació possible figurada. En van ser útils exemples:

- Com és què això es troba en un museu? Qui deu decidir que això és art?

- Què creus que és millor, la democràcia que tenim o una dictadura?

- Si vols partir el cub en dos, quina figura tindries com a secció?

Aquesta tipologia de preguntes pot apuntar en moltes direccions. En general, ajuden també a trobar raons, avals o a preveure refutacions en el discurs argumentatiu.

e) Preguntes relacionades amb l'extensió o generalització de les respostes.

Es tractava de fer veure en quines condicions s'emmarcava el discurs argumentatiu concret, en el sentit de si es podia generalitzar a més condicions de les explicitades o no. És a dir, són preguntes que fan reflexionar al subjecte sobre el grau de generalitat de la seva resposta. En general s'enuncien d'una manera directa. En van ser exemples

- És sempre vàlida aquesta afirmació?

- Ho és per a tothom?

- És una idea general?

- Es verifica sempre?

Com es pot comprovar, van ser preguntes que apuntaven cap a la consideració de la modalitat, les excepcions i l'aval en el discurs argumentatiu.

Procediment.

Les preguntes que hem anotat anteriorment-i d'altres que no s'han explicitat-, es plantejaren en una situació d'entrevista individual oberta. Partint de la base de la tipologia de preguntes descrites, el moment i la manera concreta de ser plantejades varià en funció de les respostes donades pels alumnes. El que sí que va ser idèntic per a tots va ser la seqüència de la situació d'entrevista, que pautem tot seguit: 1) Es lliurà a l'alumne el full amb la seva argumentació. Se li demanà que el llegís. 2) Es demanà el seu grau d'acord amb el que va escriure i se'l convidà que hi afegís alguna cosa més si calia. Va ser el moment en què es plantejà la pregunta de revisió de l'argumentació prèvia.

- Vas dir que.... Estàs d'acord amb el que vas escriure o hi afegiries, canviaries o trauries alguna cosa?

3) S'inicià la conversa plantejant els diversos tipus de preguntes (fonamentadores, focalitzadores, d'hipòtesi, d'extensió o generalització de les respostes) i es van anar formulant noves preguntes en funció de les seves respostes.

- "Sempre va així? Hi ha alguna excepció al que dius? Quina? Què et fa pensar així? En què et bases per dir això? Podries precisar aquesta idea?
Això que has dit ara coincideix amb el que vas escriure? Pots posar exemples per donar suport a la teva idea?

4) Es convidà l'alumne a refer la primera argumentació en els termes següents:

- Després d'aquesta conversa, voldries modificaro afegir alguna cosa a la teva argumentació anterior?

Les entrevistes van estar enregistrades i posteriorment transcrites. Alguns fragments il.lustratius de la tipologia de preguntes i de l'anàlisi de resultats que mostrarem a continuació han estat extrets de les citades transcripcions.

\section{Exemples i comentari sintètic de la interacció pregunta- resposta en les diferents àrees}

En aquest apartat presentarem exemples pràctics de les preguntes que acabem de definir, agafant preguntes ( $E$, entrevistador) i respostes ( $P$, participant) de cada àrea. També hi afegirem un comentari de l'entrevistador, que planteja una primera anàlisi de la interacció entre la pregunta i la resposta. Seguirem l'ordre de l'apartat anterior, el 2.

3a) Revisió de l'argumentació prèvia.

Recordem que eren preguntes de l'inici del diàleg que es responia a través de les següents.

3b) Preguntes fonamentadores.

Exemple d'Educació visual i plàstica:

- (E) Tu quan dius que "hi ha idees equivocades sobre art", com arribes a aquesta conclusió? En què et bases per dir això?

- $(P)$ Jo he dit aquí que la gent es pensa que l'art és simplement allò clàssic... és que clar, jo tampoc puc saber si una obra és art o no. Però en el moment en què tu ho fas amb un sentiment, volent expressar alguna cosa, això, no sé si s'arriba a considerar art, o és que uns altres consideren la teva obra art. És que no ho sé, fins a... si tu pots considerar que el que tu fas és art, o... m'entens? A vegades potser jo penso que faig una obra d'art i tu te la mires i diràs: "no, això no és res". M'entens?

Comentari sintètic: La pregunta va implicar que el subjecte es reafirmés en el que havia escrit, tot i que sembla que produí algunes raons, desenvolupant lleugerament el raonament inicial que havia escrit.

Exemple de Ciències socials:

- (E) Per què no t'agrada la democràcia que hi ha a Catalunya? En què et bases per afirmar-ho?

- $(P)$ Perquè diuen que es farà no sé què i no ho compleixen. Tu vas a votar i guanya un partit i no governa. No hi ha democràcia ara.

Comentari sintètic: La pregunta va servir per a ampliar raons, però es notà que l'alumne tenia un component que feia difícil l'ampliació: haver passat recentment per 


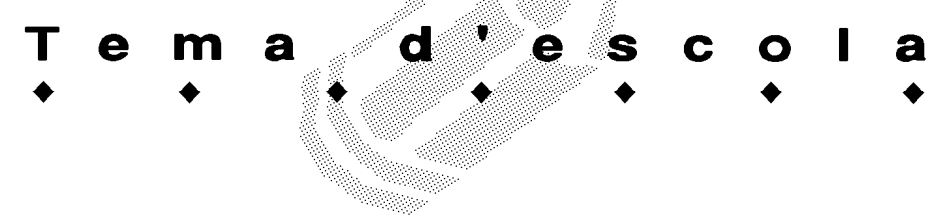

una votació al Parlament i no estar d'acord amb els resultats. No entenia que un partit, ni que guanyi un procés electoral amb més vots, pot no acabar governant per la possible suma d'entesa de les altres forces. Això implicà que les raons les veiés totes negatives i que bescantés fins el procés.

Exemple d'Educació física:

- (E) Dius que les activitats físiques són necessàries per a portar una vida saludable. En què et bases per dir això?

- (P) Doncs perquè si no fas activitat física et pots lesionar fàcilment.

- (E) Pots concretar-ho més?

- (P) En la nostra societat depèn del que treballes: si tu treballes de repartidor i vas amb bicicleta, ja fas activitat esportiva, però si tu treballes, com actualment treballa la major part de la gent, en una oficina assegut, doncs no fas gens d'esport, això a la llarga penso que pot provocar moltes lesions d'esquena, lesions de cames $i$ si has de fer un esport ràpid de córrer et pots lesionar fàcilment [i a part penso que la dieta mediterrània és sana, però penso que si no fas cap tipus d'activitat $i$ estàs tot el dia assegut fent un treball sedentari t'acabes engreixant, que al cap i a la fi fins a un cert punt és normal, però si passes dels límits engreixant-te, el sobreprès no és saludable perquè pots tenir infarts].
Comentari sintètic: El tipus de pregunta va implicar que l'entrevistat es reafirmés en la seva posició anterior, però aportant més raons i més consistents en relació amb el primer escrit, tot i que hi afegí una raó al final de l'argumentació que es desviava de l'afirmació donada.

Exemple de Matemàtiques:

- (E) Estàs segura que la diagonal del cub no és igual a la diagonal de la cara? Per què?

- (P) La resposta meva és correcta, però les raons no són clares. El que diré jo ara és que si la diagonal del quadrat és més gran que un d'aquests dos quadrats, llavors la diagonal del cub és més gran que un dels costats del cub; com que la diagonal del cub té en compte la llargada i l'altura i la profunditat, sumes les tres i dóna més.

- (E) Què vol dir això que sumes les tres? Parles de com es calcula.

- (P) Per calcular la diagonal del cub haig de tenir en compte tres factors: la llargada, l'alçada i l'amplada, i per això ocupa més que la diagonal del quadrat.

Comentari sintètic: En aquesta pregunta de matemàtiques s'observà que l'entrevistada era capaç de visualitzar espacialment la figura i les dues diagonals de què es parla, però no era capaç de verbalitzar-ho correctament, com es pot observar per la resposta. Per aquesta raó creiem que serien necessàries moltes preguntes de devolució que l'ajudessin a clarificar l'expressió verbal.

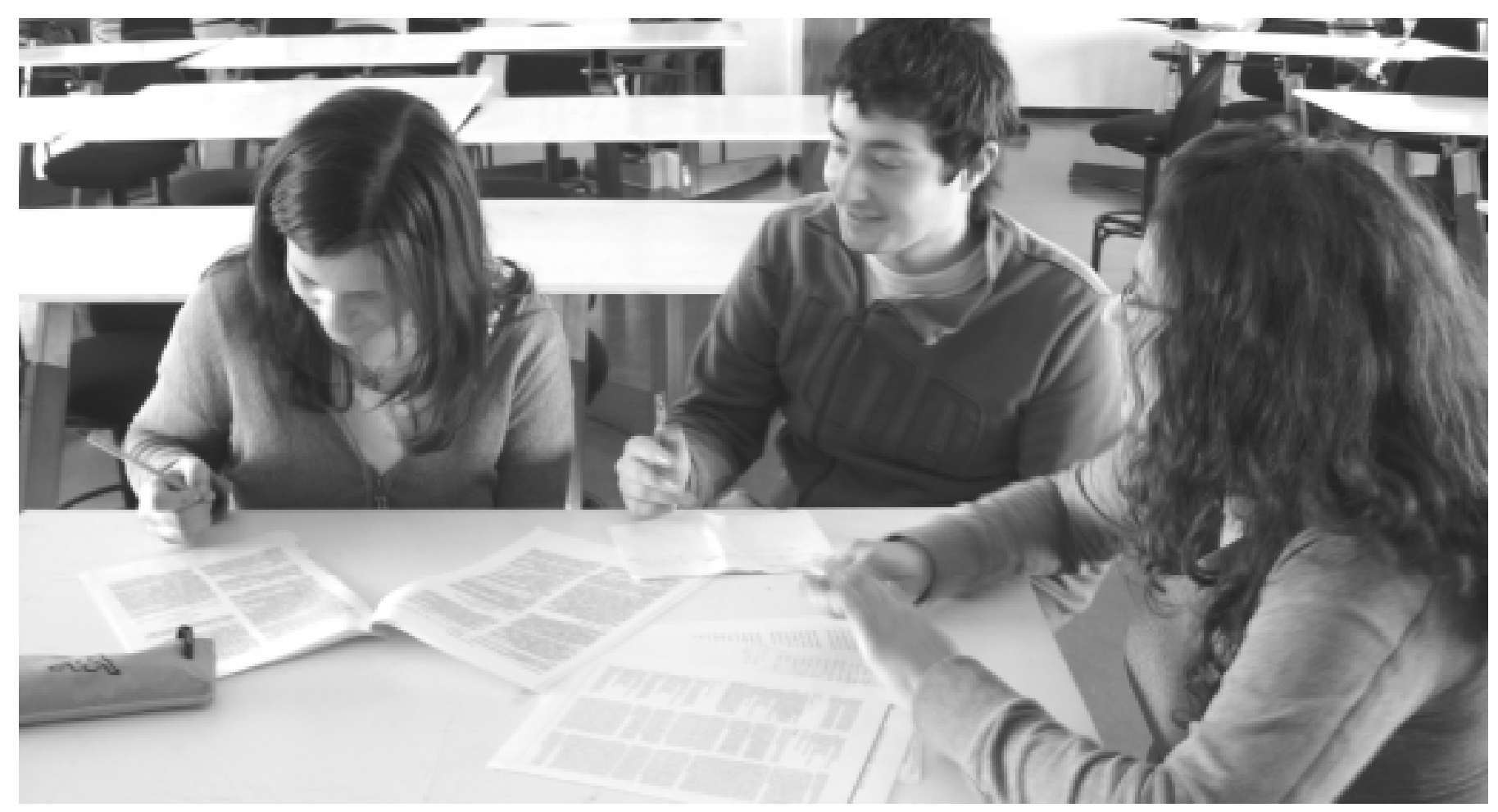




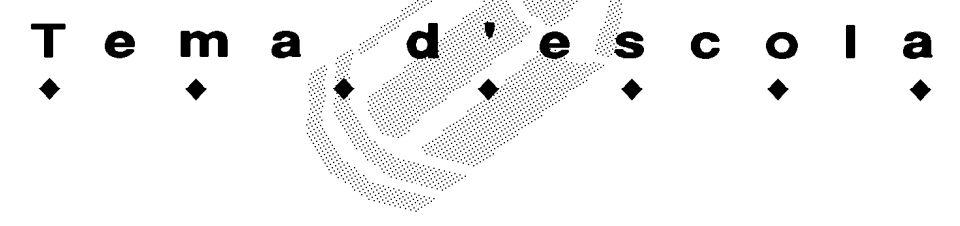

3c) Respecte a les preguntes de devolució aportem una mostra prou clara i eloqüent d'alguns alumnes a l'àrea d'Educació visual i plàstica.

En la següent seqüència, la pregunta de devolució féu més explícita una idea intuïtiva de l'art de tipus formalista, que ja es veia evident entre línies a la primera resposta. L'alumne va dir:

- $\left(P_{2}\right)$ Potser sóc antiquada o molt tradicional, però crec que l'art per a mi és... jo què sé, gaudeixo més veient quadres o... escultures que no pas per exemple veient això, no? Unes cadires penjades, uns ventiladors... potser la meva és una idea més tradicional, però una obra així tan moderna, no m'agrada, no? I si ho hagués d'ensenyar als nens no crec que els ensenyés això. Faria potser obres més... no sé, més... no més complicades sinó, un Picasso, o alguna cosa així, perquè vegin que és més complet, és més treballat. Potser és... no és que sigui més simple, però no ho veig com a art. Perquè crec que això ho pot fer qualsevol.

Comentari sintètic: L'entrevistada es planteja, per primer cop, que ella parteix d'una perspectiva determinada: "potser la meva és una idea més tradicional".

- (E) Tu arribes a aquesta conclusió, que això no és art, perquè... és simple...

- $\left(P_{2}\right)$ Clar, és simple, ho pot fer qualsevol persona i perquè no té cap treball, ni cap cura ni... ha mirat les formes, els colors. És agafar coses que tens a l'abast $i$, aquest, per exemple, posar-les boca per avall. Jo crec que l'art ha de ser una forma més treballada, mirant els colors, les formes...

Comentari sintètic: Aflora una teoria implícita, que és la visió formalista de l'art.

Com en l'exemple anterior, la devolució implicà que l'alumne se centrés en el tema i fes més explícites les idees que s'entreveien a la resposta anterior.

3d) Preguntes focalitzadores.

Exemple d'Educació visual i plàstica:

- (E) I tu creus que tothom pensaria el mateix? Dius que això no és art, perquè són quatre cadires... Creus que tothom pensaria el mateix?

- $\left(P_{t}\right)$ [rotunda] No.

- (E) Qui no pensaria el mateix, per exemple?

- $\left(P_{1}\right)$ La persona que ho ha fet. I si llavors es troba en un museu o ho tenen exposat és perquè... vull dir... té algun significat o... té algun sentit perquè ho hagi fet així d'aquesta manera.

- (E) És a dir, que per a algunes persones això deu ser art, $i$ aquestes persones deuen ser... qui? Qui pot pensar que això és art? A qui li pot interessar això?

- $\left(P_{1}\right)$ Doncs a gent que hi entén, no? Potser a professors també d'història de l'art o gent així.
Comentari sintètic: La sèrie de preguntes per a plantejar òptiques alternatives -focalitzadores- va funcionar, i l'entrevistada va admetre que per a altres i per al mateix autor sí que deu ser art. Això ja ho expressava a l'argumentació inicial, però amb la darrera pregunta tornen a aparèixer els experts, que ara es categoritzen com a "professors d'història de l'art o gent així".

Exemple de Ciències socials:

- (E) Creus que totes les democràcies són bones? Sempre la democràcia és millor que la dictadura?

- (P) Jo no he viscut el temps de la dictadura. No sé com va ser realment, però pel que he escoltat sempre són coses negatives. El que veig ara no és negatiu com la dictadura.

Comentari sintètic: L'alumne es planteja una altra situació possible, la compara amb el present i dóna una opinió molt general.

Exemple d'Educació física:

- (E) Et bases en algun referent-autor o col-lectiu professional- per reforçar això que dius?

- (P) Jo sempre he fet esport i m'agrada l'esport. He fet handbol molts anys, no sé, a part he fet algun curset d'entrenador, bàsicament les idees que tinc les trec d'aquí, però a part ja és de sentit comú, perquè sempre he sentit a casa que fer esport és saludable, no sé, la meva mare pensa que he d'estudiar però sempre m'ha dit que l'esport és un bon complement dels estudis, perquè l'estudi és una cosa molt sedentària i l'esport t'ajuda. La meva mare $i$ les entitats esportives han estat potser les que més m'han induit a tenir aquest pensament.

Comentari sintètic: En aquest cas la pregunta no ha servit per a ampliar el punt de vista. L'entrevistat fa ús d'idees adquirides principalment a nivell informal, el seu entorn familiar i la seva pràctica esportiva; tot i que diu que ha fet algun curset d'entrenador, en la seva resposta no fa esment específic d'un coneixement més formal. Per tant, aquesta pregunta no l'ha fet situar més enllà de la seva perspectiva personal.

Segurament és característic d'aquesta àrea de coneixement que es pugui argumentar des d'una perspectiva informal donada la gran quantitat d'informació que hi ha al respecte en la societat actual.

Exemple de Matemàtiques:

A fi que l'entrevistada pugui cercar un grau de generalització més alt, li plantegem poder calcular les longituds que cal comparar.

- (E) Com es podria calcular la diagonal si coneixes l'aresta del cub?

- $\left(P_{2}\right)$ Si sé quant mesura això... (pensa), el podria calcular per Pitàgores.

- (E) On veus tu l'angle recte? 


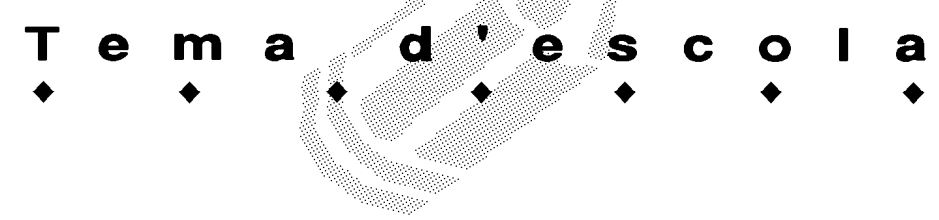

- $\left(P_{2}\right)$ Aquí és l'angle recte. Doncs així podria calcular la diagonal de la cara i si sé aquesta, ja puc calcular la diagonal del cub. Faria altra vegada Pitàgores.

Comentari sintètic: Aquesta tipologia de pregunta va dur l'entrevistada a trobar o recordar un procediment per calcular les dues llargades. Procediment que al verbalitzar-lo implicà que s'adonés de la raó fonamental que justificava l'afirmació.

3e) Preguntes d'hipòtesi.

Exemple d'Educació visual i plàstica:

L'entrevistada afirmà no saber quin era el procés pel qual una obra com la de la fotografia era en un museu. Quan se li demanà que aventurés "què deu passar perquè això sigui així", es plantejà possibles valors de l'obra-encara que fos com a hipòtesi- que havia menystingut inicialment.

- (E) ¿Aleshores, com és que aquest muntatge es troba en un museu? Qui deu decidir que això és art?

- $\left(P_{2}\right)$ No ho sé. Perquè el que a mi em sorprèn és que fan coses així $i$ a la gent li agrada $i$ ho va a veure, i es fa famós l'artista...

- (E) Però per què deu passar? Tu per què creus que passa?

- $\left(P_{2}\right)$ Potser perquè són coses diferents. Estem acostumats a veure sempre el mateix, $i$ al fer una cosa innovadora a la gent l'atreu. Però no sé... A veure, sí que atreu veure-ho, perquè són coses noves, són coses diferents que no has vist abans, però fins al punt de considerar-ho art, no crec.

Comentari sintètic: Apareix un aval nou: la innovació com a criteri de valor en l'art.

Exemple de Ciències socials:

A l'entrevistada se li plantejà la hipòtesi de dictadura o democràcia, a partir de dubtes del que havia respost.

- (E) Tu què creus que és millor, la democràcia que tenim o una dictadura? Una dictadura seria millor?

- (P) La democràcia que tenim. Almenys avançarem, no, se suposa? I estem perquè canviï, no? Almenys s'ha expressat l'opinió a les eleccions, no de la majoria de ciutadans, però sí d'alguns. Si hi hagués una dictadura, ja no sabries el que la gent voldria.

- (E) Per tant és millor la democràcia que tenim...

- (P) Però no és la que hauríem de tenir.

Comentari sintètic: Al plantejar-se-li la hipòtesi té clar que el procés electoral ajuda a decidir sobre unes persones i partits que es vol que ens administrin. Remarca que si no hi hagués un procés electoral, el poder de decisió sobre les persones que haurien d'administrar la cosa pública seria nul. Tot i així, és crítica amb el sistema democràtic.

Exemple de Matemàtiques:
L'entrevistada parla d'una línia que parteix el cub en dos. Davant la imprecisió del seu llenguatge es provoca aquest diàleg:

- (E) Si volguessis partir el cub en dos, què hauries de fer?

- (P) Doncs baixar d'aquí a aquí i d'aquí a aquí... mostra el dibuix.

- (E) I això com es diu... És una línia o una figura plana?

- (P) El tall? Una línia només no, és un pla sencer.

- (E) Quina figura et sortiria si partissis el cub com tu dius?

- (P) Quedarien cares rectangulars.

- (E) Dos costats més llargs i dos més curts... un rectangle.

Aquest rectangle quina relació té amb la diagonal del cub que tu has dibuixat? Agafa el llapis i dibui$x a$ 'l si et cal.

- (P) Quedaria així -mostra el dibuix correcte.

Comentari sintètic: Per a aquesta qüestió l'entrevistada necessita l'ajuda del dibuix. En aquest cas les preguntes d'hipòtesi fan que ella amplii el seu punt de vista i s'adoni de més relacions mètriques en la figura.

3f) Preguntes relacionades amb l'extensió o la generalització de la resposta.

Exemple d'Educació visual i plàstica:

La participant ha manifestat que la imatge que se li ha mostrat no la considera art, i l'entrevistador qüestiona la generalitat d'aquest punt de vista:

- (E) Creus que és una idea general? Tothom seria del mateix parer?

- $\left(P_{2}\right)$ No. No crec que tothom pensi el mateix. Jo el que penso és que potser tinc una idea d'art massa tradicional, no? Però no sé... l'any passat quan ens vas ensenyar també aquelles parets que estaven totes escrites en un museu, per a mi allò no és art. És expressar, potser, el que sent una persona, però no ho consideraria com a art.

Comentari sintètic: Pregunta que torna a incidir en la subjectivitat del punt de vista de l'entrevistada, i fa revisar la validesa del que diu. De nou reconeix una presa de posició personal: "potser tinc una idea d'art massa tradicional".

Exemple de Ciències socials:

- (E) Això voldria dir que a la democràcia funciona sempre tot bé?

- (P) No. Tot suposo que no. Jo em baso en el que visc $i$ en opinions que he escoltat.

- (E) A què et refereixes?

- (P) En entrevistes que he vist per la tele, en el que he comentat amb la meva família, tot el que es diu en els llibres. La dictadura és una cosa negativa. 


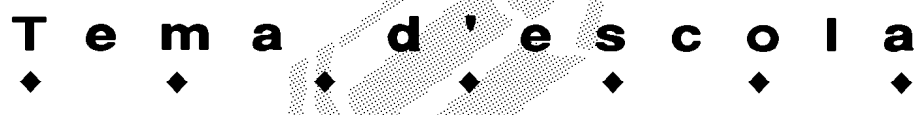

Comentari sintètic: L'alumne a partir de la pregunta esdevé conscient que pot parlar només d'allò que ha vist, tot i que té clar que la dictadura no és un sistema polític adequat.

Exemple d'Educació física:

En aquest cas es partí d'agrupar les preguntes d'hipòtesi-fer o no l'activitat física adequada a la persona que la realitza- amb les preguntes relacionades amb l'extensió i la generalitat en aquest apartat. En sortí aquesta conversa:

- (E) Tu penses que l'activitat física és sempre beneficiosa per a tothom?

- (P) Jo penso que és bo que no es passin uns límits, com tot, o sigui, el que està clar és que si et passes fent activitat física, al final no pot ser bo perquè de molt forçar pots tenir lesions; pots, fins i tot, si tu no saps on són els teus límits, si vols seguir fent esport, pots arribar a tenir un problema cardiovascular, que molta gent s'ha mort de mort sobtada per passar-se fent esport, per no conèixer els seus límits. Penso, a veure, que sempre serà beneficiós en funció de com s'apliqui. Si tu tens moltes lesions al cor i no pots posar-te al límit, doncs pots fer un altre tipus d'activitat física més tranquil-la, del tipus "aigua-gym", que són moviments més controlats que no arriben a desgastar molt anaeròbicament, allò d'ofegar-te.

Comentari sintètic: Es veu que els entrevistats matisen els beneficis de l'activitat física en funció de les característiques de la persona que la practiqui i sempre que no se n'abusi. Conseqüentment, aquest tipus de pregunta millorà l'argumentació al contemplar les excepcions o refutacions de l'afirmació general.

El mateix es va poder observar en la següent resposta, tot i que en aquest cas es basà en l'experiència personal.

- (E) Estàs d'acord que l'activitat física i esportiva és sempre saludable per a tothom?

- $\left(P_{3}\right)$ L'esport és saludable, però fins a un límit, tot té la seva mesura. També depèn de cadascú, del cos. En principi és saludable practicar-lo regularment. Però jo, que he fet gimnàstica rítmica, no he pogut continuar per mal d'esquena. A base de fer competicions descompenses l'esquena i això no afavoreix el cos. Has de fer natació per compensar les extremitats.

Exemple de Matemàtiques:

L'entrevistada manifesta poca seguretat en les seves respostes a la pregunta, però apunta l'existència d'una llei general descrita per una fórmula.

- (E) Es verificarà sempre això que tu afirmes?

- $\left(P_{3}\right)$ Canviaria l'expressió, però l'argument és el mateix: jo trobo que la diagonal del cub és més llarga que la diagonal d'una de les cares.

- (E) Sí, però això és una afirmació que no està justifi- cant el perquè. Com es pot justificar...?

- $\left(P_{3}\right)$ S'hauria de fer amb una fórmula, crec jo.

Comentari sintètic: Encara que diu no recordar la fórmula, manifesta en l'entrevista que a l'escola es feien servir fórmules per calcular la diagonal d'un cub. Per tant, té clar que és una idea generalitzable.

\section{Valoració de l'estratègia de la formulació de preguntes per millorar l'argumentació en cada àrea}

Un cop realitzat el procés de preguntes-resposta, l'equip es plantejà fer una valoració de l'estratègia seguida i, alhora, del que succeí en el procés interactiu professor de magisteri-alumne de magisteri. L'anàlisi implicava ambdues facetes: veure com resultaven les diverses tipologies de preguntes classificades per fer avançar l'alumne cap a una comprensió més eficaç, i segonament observar quin canvi argumentatiu s'havia aconseguit en l'alumne. Això és el que en sortí, a les diferents àrees de treball.

Educació visual i plàstica.

En línies generals, les preguntes han contribuït a desenvolupar l'argumentació inicial. A través de la interacció pregunta-resposta, els participants han anat més enllà de les respostes basades en opinions i preferències no raonades, i han fet emergir de forma més o menys explícita algunes de les teories intuïtives en què es basaven els punts de vista expressats.

Les preguntes fonamentadores han servit, en tots els casos, per a reafirmar i desenvolupar les raons que sustentaven l'afirmació. Al fil de les preguntes que demanaven "en què es basa" per arribar a una determinada conclusió, sovint han aparegut raons no contemplades a l'argumentació inicial. La mostra estudiada ha apuntat, doncs, que en educació artística les preguntes fonamentadores poden afavorir la diversificació de les raons adduïbles per a donar suport a una afirmació. Permeten anar més enllà del patró "A, perquè $B$ ", en la forma de raonament causal més simple. No obstant això, cal subratllar que aquestes preguntes contribueixen a diversificar les raons, però no en milloren la qualitat o la pertinença.

Les preguntes focalitzadores i les de generalització han servit, en alguns casos, perquè els participants es plantegin la universalitat del que afirmen. Una afirmació contundent sense una base suficient ha estat revisada pel subjecte quan se li proposa un enfocament alternatiu o se li demana si el que diu és vàlid "sempre" i "per a tothom". Aquest tipus de preguntes són especialment útils, en el terreny estètic, quan l'entrevistat està parlant a partir de prejudicis. També en els casos en què l'alumne enunciava opinions subjectives com si fossin lleis universals, les preguntes focalitzadores han resultat adients: resituen el tema davant el participant fent-lo conscient 


\section{T e ma, d: e c o I a}

que el que diu és, en realitat, la seva manera de veureho. En conseqüència, contribueixen en la producció de modalitats i refutacions -quan la pregunta fa emergir dubtes respecte a la validesa de l'afirmació-, i també d'avals quan la pregunta indueix a plantejar el tema en termes menys particulars i a transcendir la mera opinió personal fent recurs a lleis o consensos més amplis.

Les preguntes d'hipòtesi han resultat menys eficaces del que es podria preveure. Tot i que en algun cas han aportat perspectives possibles no previstes inicialment, els participants més aviat han tendit a reafirmar les seves idees en els contextos plantejats. En algun cas també la hipòtesi plantejada ha provocat la inhibició de l'entrevistat: com que la situació és hipotètica, afirma "no saber què passaria".

Tot i que els coneixements que l'alumne posseeix sobre un tema limiten la seva capacitat argumentativa, la interacció pregunta-resposta pot contribuir a enriquir el raonament. En l'experiència realitzada en educació visual i plàstica, en tractar-se d'una qüestió oberta, d'apreciació estètica, destacaríem la utilitat de proposar enfocaments possibles i revisar la universalitat del que hom diu. Aquest tipus de qüestions obren vies interessants per a desemmascarar teories implícites que perjudiquen sovint les possibilitats de comprendre noves dimensions d'un fenomen complex com són les arts visuals.

Ciències socials.

L'experiència d'abordar una reflexió dirigida a atacar els punts febles del raonament social ha servit per constatar, en línies generals, que els alumnes que tenen una base conceptual sòlida del tema o de la valoració personal que es demanava a la pregunta, han seguit conservant-la i alhora l'han ampliat, aportant només matisacions del concepte, sense desvirtuar la seva adequada reflexió.
Altrament, però, també ha servit per a comprovar que els alumnes amb una feble argumentació han reiterat conceptes equívocs, amb estereotips impropis de futurs professionals de l'ensenyament, demostrant que si la base doctrinal és dolenta fins s'arriba a desvirtuar els continguts. Finalment, cal assenyalar que només en els alumnes amb base conceptual fluctuant s'ha incidit com calia, i ha millorat la seva argumentació ostensiblement.

Les preguntes fonamentadores, per ampliar, matisar i donar raons noves han servit per a demostrar on era cada alumne. Només els alumnes amb una nebulosa conceptual han aconseguit millorar algunes raons, tot i que cal remarcar els tombs per arribar a la finalitat que es buscava, a part de les preguntes de devolució que han servit de pretext per a incitar el diàleg. Ha estat significatiu el cas d'alumnes amb escassa capacitat de revisió dels seus tics, potser perquè es tractava d'una qüestió interpretativa més que no pas explicativa. En conjunt, malgrat l'apuntat, ha servit per a situar cadascú amb escassos avanços.

Les preguntes focalitzadores, en el cas interpretatiu i personal que ens ocupa, han servit per a qüestionar-se aspectes que havien sortit a partir d'un punt de vista nou i alternatiu. En general, s'ha notat que l'interrogant ha planat en alumnes amb una reflexió poc convincent, però s'ha observat que les idees mal preconcebudes han suposat un fre. Cal manifestar, tanmateix, que els alumnes amb dubtes no greus han pogut qüestionar-se un punt de vista deformat parcialment.

Les preguntes de generalització han evidenciat el reduccionisme dels alumnes amb febles respostes sobre la qüestió de la pregunta inicial. S'ha constatat aquest reduccionisme en la dificultat de sortir de l'àmbit territorial propi, de presentar només problemes propis... implicant

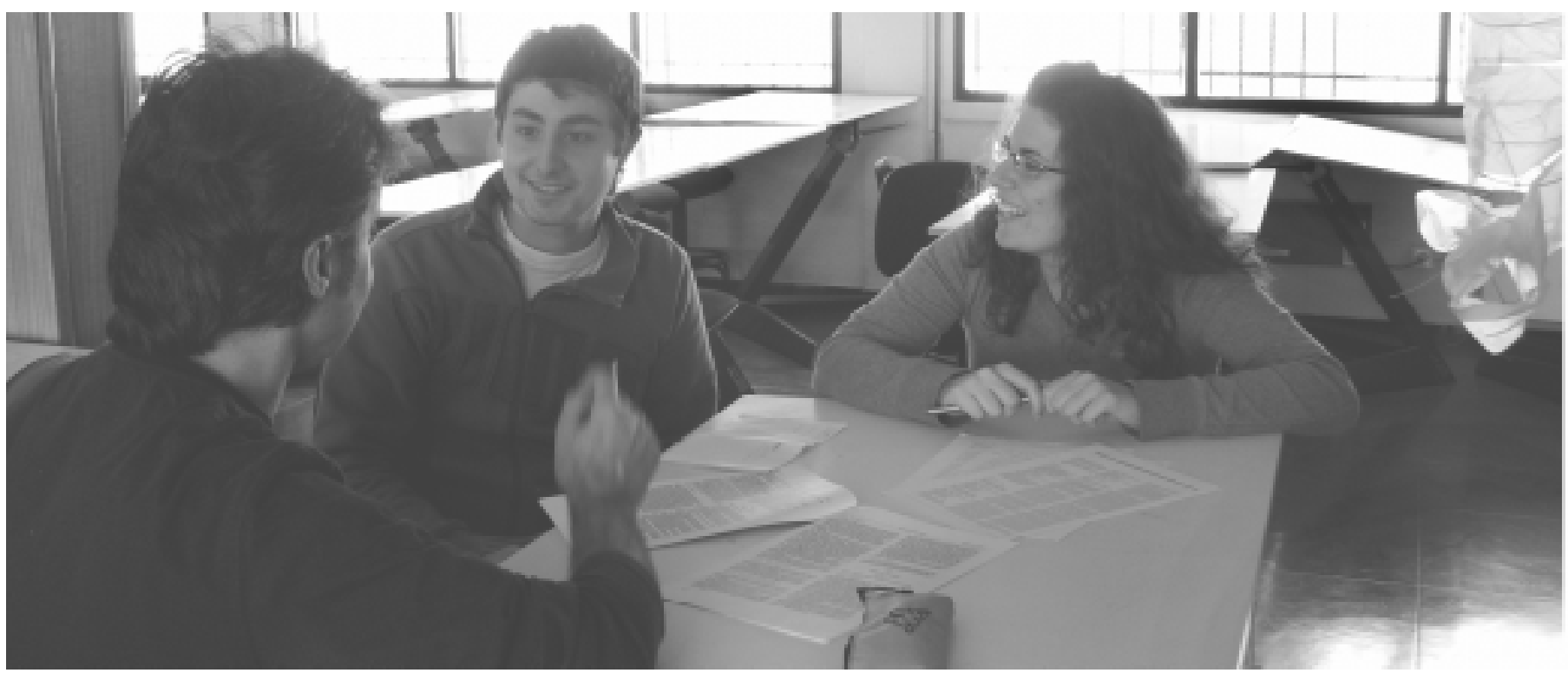




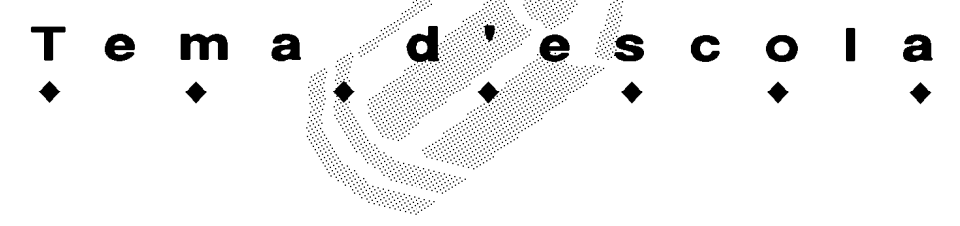

una escassa reflexió del que succeeix al món, en el problema que es presentava. En el cas dels alumnes amb base històrica assumida, el discurs ha permès comprovar que poden fer transposicions a altres realitats, sense problemes.

Les preguntes d'hipòtesi han buscat fer adonar als alumnes de respostes amb una base poc estructurada, per mirar de recuperar el fil argumental del que es demanava, a partir d'una situació possible figurada. S'han visualitzat en alguns casos extrems respostes excessivament curtes, com si els costés entrar en el tema. En altres casos les connexions han servit per a estimular qüestions que no havien previst, i s'ha millorat eficaçment i variat l'argumentació. En alguns casos han precisat reformulacions que han ajudat a una argumentació més convincent i assumida.

Amb tot el que queda exposat pot dir-se que les preguntes han incitat l'alumne a intentar una argumentació de més qualitat, aspecte que no s'ha vist projectat al moment d'escriure-ho, posant només deficients justificacions del que s'havia redactat en una primera instància.

\section{Educació física.}

La valoració de les preguntes i la interacció establerta entre l'entrevistador -expert- i l'entrevistat, tot i que no és homogènia, es pot considerar força positiva. Les qüestions que han guiat el diàleg han afavorit la reflexió i han permès el raonament de les seves opinions. En la majoria de casos, ha millorat lleugerament el discurs inicial, aportant nous elements de l'estructura argumentativa.

Amb les preguntes fonamentadores tots els participants s'hi han reafirmat, aportant noves raons i desenvolupant o matisant les idees del discurs que havien escrit. Tot i que en algun cas han portat l'entrevistat a fer una nova argumentació -allunyada de la qüestió plantejada inicialment-, aquest tipus de preguntes, així com les de devolució han servit per a ajustar i/o ampliar l'argumentació.

Les preguntes de generalització han servit perquè els participants es qüestionessin i reflexionessin sobre el grau de generalitat del que afirmaven. En aquest cas, tot i que "sempre" estava inclòs en la qüestió plantejada, fins que no se'ls ha demanat explícitament si el que deien era vàlid "sempre" i "per a tothom", no ho han tingut en compte, ni tan sols s'han plantejat possibles excepcions. En termes generals, es destaca la utilitat d'aquest tipus de pregunta que els fa plantejar interrogants sobre la validesa de l'afirmació. Han enriquit l'estructura argumentativa generant nous elements no contemplats fins al moment: refutació i modalitat.

També cal destacar que no s'ha obtingut el resultat esperat pel que fa a les preguntes focalitzadores o d'hipòtesi. En les preguntes focalitzadores ha estat difícil que els entrevistats adoptessin una òptica diferent de la pròpia, que és el que es pretenia amb aquest tipus de pregunta. No han aportat teories o explicacions d'experts dels camps de coneixement de l'educació física -avalsper consensuar l'afirmació donada -qui ho aconsella, per què...?-. Han mantingut arguments basats en aspectes personals, en casos particulars i en opinions subjectives.

L'estratègia de les preguntes ha estat vàlida per enriquir algun aspecte de la capacitat argumentativa. S'ha produït una lleugera millora pel que fa als elements de l'estructura. En canvi, no han contribuït a millorar la qualitat del raonament i de l'expressió.

El coneixement propi de l'àrea sembla insuficient, fet que evidencia que els coneixements previs limiten la capacitat argumentativa. En aquest sentit, el progrés suscitat per la interacció pregunta-resposta ha estat poc significatiu, manquen aportacions amb arguments més consistents i utilitzar un llenguatge més científic. Una bona argumentació no pot basar-se tan sols en raons particulars, també s'ha de fonamentar en criteris científics acceptats socialment.

\section{Matemàtiques.}

Es valora positivament la interacció o diàleg entre el que aprèn i el punt de vista de l'expert per a millorar la comprensió de la tasca que es demana i fer-la, aportant les raons, els avals i els altres elements pertinents de l'estructura argumentativa.

La tipologia de preguntes que millor s'ha adaptat a aquesta tasca concreta han estat les preguntes fonamentadores, ja que gràcies a elles els entrevistats acoten els significats dels termes emprats. Com ja s'ha dit a l'apartat anterior, aquesta és una dificultat important en les argumentacions dels alumnes, i la circumstància de no utilitzar els termes de manera precisa ha fet que fossin necessàries moltes preguntes de devolució per a ajudar a precisar el concepte.

Les preguntes focalitzadores han comportat que l'entrevistat adoptés un altre punt de vista. En aquest cas concret la pregunta de major ajuda ha estat induirlos a pensar com es poden calcular aquestes dues llargades. A l'intentar trobar un mètode per calcular-les s'han adonat que necessiten visualitzar certes construccions geomètriques, conèixer les relacions mètriques en un triangle rectangle i veure per a aquest cas la pertinença de la seva utilització.

Les preguntes d'hipòtesi. En el discurs argumentatiu que anà construint l'entrevistat aparegueren situacions de descripció de relacions espacials -"aquesta línia parteix...."-que féu pertinent establir hipòtesis com: "Què caldria fer per tallar el cub en dues formes congruents? Quina ens serveix per a parlar de les diagonals?". Aquestes qüestions que requereixen manipular mentalment 


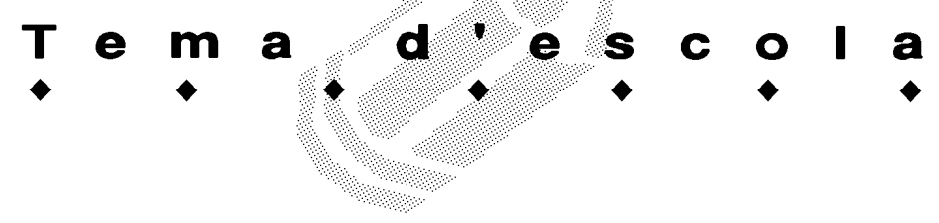

els conceptes, captar relacions directes i inverses i en general establir gran quantitat de connexions han estat sempre de gran utilitat en aquesta àrea.

Cal assenyalar, finalment, que malgrat observar una certa millora en la capacitat argumentativa induïda per les preguntes, s'ha continuat constatant una insuficiència conceptual i expressiva per poder fer un discurs argumentatiu segons els principis lògico-deductius que requereix aquesta qüestió matemàtica.

\section{Valoracions finals}

Comptat i debatut, sintetitzaríem la proposta en unes reflexions que permeten prefigurar resultats d'avui i possible investigació de futur:

- Les preguntes com a estratègia per desenvolupar l'argumentació apunten possibilitats interessants que caldria continuar explorant en treballs posteriors. En la majoria de casos, els participants amplien i diversifiquen les raons a partir de les preguntes. Alguns participants fan una reformulació del seu punt de vista inicial, plantejant-se excepcions (refutació) o matisant el seu grau de certesa en relació amb el que afirmen. Cal dir, però, que en pocs casos les preguntes han servit per a fer aflorar lleis generals o sabers estructurats propis d'un camp de coneixement (aval, teoria). Aquest darrer aspecte pensem que té relació amb el nivell de coneixements dels participants quant al contingut de les diverses àrees implicades. Òbviament, hom no pot argumentar basant-se en principis, teories 0 lleis avalats per la ciència si no els coneix.

- A l'ensenyament de Mestre, especialitat d'educació primària, hi ha un segment d'alumnes -pocsque argumenten amb solvència i eficàcia; un grup més nombrós argumenten de forma genèrica, sense categoria, i un tercer grup -bastants- que no argumenten res del que se'ls pregunta.

- L'alumne que argumenta molt bé en una àrea, normalment segueix amb la mateixa tònica en altres àrees, o com a molt fluixeja en una sola, demostratiu que el procés argumentatiu el té assumit. A l'àrea que presenta dificultats s'hi constata que falla l'aparell conceptual de la pregunta.

- L'alumne que argumenta bé en unes àrees i malament en altres demostra que quan falla ho fa en l'estructura conceptual d'àrees que no li permeten entendre la pregunta formulada o que té una inventiva que li fa escriure qüestions sense fonament, demostratiu que l'exercici oral no és gaire present a les aules i que el predomini de l'escrit el fa ser intuïtiu i agosarat, la majoria de les vegades sense dir absolutament res.
- L'alumne que no construeix discurs argumentatiu o simplement no argumenta res demostra, en una primera impressió, que no té continguts conceptuals assumits com es podria esperar d'haver superat unes etapes d'escolaritat prèvies a la universitat.

- L'exercici oral serveix, en moltes ocasions, per a demostrar les mancances de l'escrit, i en d'altres ha estat un revulsiu que ha fet reformular conceptes. Tant en un cas com en l'altre constatem que és del tot necessari per avançar raonadament, buscant la comprensió i l'excel-lència.

- Hem comprovat que la interacció pot resultar positiva si es tenen uns ancoratges on agafar-se, i que sense aquests es fa difícil precisar un possible avenç sòlid argumentatiu.

- Postulem, vistos els resultats, establir exercicis argumentatius a la classe, més d'acord a fer adonar als alumnes de possibles mancances, a partir de preguntes que tinguin aquest sentit instructiu i educatiu. Això implica, alhora, recuperar l'estudi de la ciència com a base de coneixement, així com fer passar per algunes proves orals els estudiants de Magisteri, en format de pràctiques de classe, proves, exposicions, exàmens, etc. Aquestes pràctiques s'haurien de regular, atès que una de les feines del mestre és ensenyar a argumentar, i poc ho podrà activar en alumnes de primària si no en tenen bases suficients, contrastades. La solució passaria per detectar aquesta mancança, ja de bon començament $\mathrm{i}$ resoldre exercicis pautats per incidir en una teràpia generalitzada a estudiants que, si segueixen en aquesta línia, auguren un perfil baix de professionals argumentatius en un futur proper.

\section{Referències bibliogràfiques}

GAVALDÀ, A., SANTISTEBAN, A., CONDE, C., GIRONDO, L., MACAYA, A. i VISCARRO, I. L'argumentació en alumnes universitaris de Magisteri de la Universitat Rovira i Virgili. Primera aportació. «Comunicació Educativa», 17 (2004) 53-57.

COLL, C. I ONRUBIA, J. Estrategias discursivas y recursos semióticos en la construcción de significados compartidos entre profesor y alumnos. "Investigación en la escuela», 45 (2001) 21-31.

GÓMEZ, A., MÀRQUEZ, C., ROCA, M., PUJOL, R. M. i SARDÀ, A. La construcción de modelos explicativos complejos mediante preguntas mediadoras. «Investigación en la escuela», 53 (2004) 71-82.

RICKERMAN, R. Las Didácticas específicas y la Educación artística. Workshop, UdG. Departament de Didàctiques específiques. 23 i 24 de novembre de 2007.

TOULMIN, S., RIEKE, R. i JANIK, A. An introduction to reasoning. Edit. McMillan. Nova York. 1997. 